\title{
The Importance of Diagnosis in Long-Term Orofacial Pain: Case Report
}

\author{
Nivaldo Vanni Filho ${ }^{1,2 *}$, Rodolfo Matsuzaki², Massimo Bompiani D'Ancora ${ }^{2}$, Antonio Sérgio Guimarães ${ }^{3}$ and \\ Luciane Lacerda Franco Rocha Rodrigues ${ }^{4}$ \\ ${ }^{1}$ Odonto Vanni Institute, Dental Surgeon, Orthodontist, Ribeirão Preto, Brazil \\ ${ }^{2}$ Masters student in TMD and Orofacial Pain at the São Leopoldo Mandic University, Brazil \\ ${ }^{3}$ Professor and Coordinator of the Graduate Program in TMD and Orofacial Pain at the São Leopoldo Mandic University, Brazil \\ ${ }^{4}$ Professor of the master's Course in TMD and Orofacial Pain at the São Leopoldo Mandic University, Brazil
}

Submission: June 15, 2020; Published: June 23, 2020

*Corresponding author: Nivaldo Vanni Filho, Odonto Vanni Institute, Dental Surgeon, Orthodontist, Ribeirão Preto, Brazil

Abstract

The high prevalence of patients with Chronic Pain, its multifactorial aspects, and the involvement of psychosocial and behavioral factors render it difficult to establish an accurate diagnosis, leading many therapeutic approaches to failure or unexpected results. The aim of the present report was to show the evolution of a clinical case of non-odontogenic pain, in which the patient described the occurrence of severe headaches in the bilateral frontal region for over a year, cervical pain, limited mouth opening, and constant tinnitus in the right and left ears. After applying the DC/TMD protocol, the patient was diagnosed with the myofascial pain subtype, with reference to pain and headache attributed to a temporomandibular disorder (TMD), in addition to tinnitus and earache. The temporomandibular joints did not present any clinical alterations in movement, sound, or arthralgia. After identifying the myofascial trigger points, manual therapy with dry intramuscular needling in the masseter and temporal muscles, electrotherapy with TENS, thermotherapy, and cervical and masseteric stretching were performed. The patient was instructed to conduct thermotherapy and stretching, at least twice a day, and, in the next session, she presented remission of headache and neck pain and a significant improvement in tinnitus.

Keywords: Research diagnosis criterium; Myofascial pain; Trigger point

\section{Introduction}

Temporomandibular disorders (TMD), which comprise orofacial pain of non-dental origin, corresponds to a collective term that covers a wide spectrum of clinical problems of the temporomandibular joint (TMJ), chewing muscles, and associated structures, that are characterized mainly by pain, joint sounds, and irregular or limited mandible function Guimarães [1]. The Diagnostic Criteria for Temporomandibular Disorders (DC/TMD) has two axes: I (physical) and II (emotional). According to the DC/ TMD, TMDs are divided into two groups: pain-related disorders and intra-articular temporomandibular disorders. The pain-related disorders group includes myalgia, local myalgia, myofascial pain, myofascial pain with referral, arthralgia, and headaches attributed to TMD. As for the intra-articular temporomandibular disorders group, disc displacement with reduction, disc displacement with intermittent locking, disc displacement without reduction with limited opening, or disc displacement without reduction and without limited opening may be present, as well as degenerative joint disease and subluxation Schiffman [2].
Myofascial Pain Syndrome is a highly complex and prevalent disorder that affects between $5 \%$ and $12 \%$ of the adult population Blasco \& Martín. This condition targets skeletal muscles and can be present in various parts of the body, including chewing muscles Gonzalez [3]. One of its primary characteristics is the presence of myofascial trigger points (MFTP), defined as hypersensitive points caused by shortening of the muscle band due to contraction, causing referred pain, which is felt in a different place from where it is produced, such as in tension headaches, and is often associated with chronic pain. MFTPs can be active, when they cause spontaneous pain, or latent, when they hurt only when stimulated Simons \& Travell [4]. In individuals with temporomandibular disorders, there is a high prevalence of MFTPs in the Masseter and Temporal muscles Blasco \& Martín [5], since excessive muscle contraction releases inflammatory chemical mediators, such as cytokines, prostaglandins, bradykinins, and substance P, which act on the receptors causing pain Stone [6]. The objective of the present study was to describe a case where the patient complained 
of a headache and was diagnosed with myofascial pain with pain referral according to the DC/TMD Axis I, who, through treatment adherence and conservative therapies, managed to control her pain.

\section{Case Report}

Patient A.C.B.B. was a 34-year-old female, who presented, as the main complaint, a throbbing headache in the frontal or bilateral temporal region for over a year. The frequency of pain was daily, although, in the morning, it presented intensity 3 on the Visual Analog Scale (VAS), which reached 9 at the end of the day. She stated that tension was one of the causes of increased pain intensity and that, during menstrual periods, the headache was accompanied by nausea. She also reported constant ringing in both ears. The patient used Dorflex ${ }^{\circledR}$ autonomously twice a day, in addition to Rivotril ${ }^{\circledR}$ for the past four years, prescribed by a psychiatrist who accompanies her every six months, due to depression and panic syndrome. During the palpation of the masseter muscle, the patient presented familial pain, with referred pain to the frontal region, resembling the previously reported headache pain. When palpating the temporal muscle, she referred pain to the auricular region. She also described pain on palpation in the cervical muscles and limited mouth opening, presenting pain when opening until $27 \mathrm{~mm}$. Stretching of the masseter and cervical muscles were performed (Figures 1 \& 2), with the aim of promoting muscle relaxation due to the stimuli of agonist and antagonist muscles Butts [7]. Next, manual intramuscular therapy with dry needling was conducted to disable the myofascial trigger points (Figure 3).

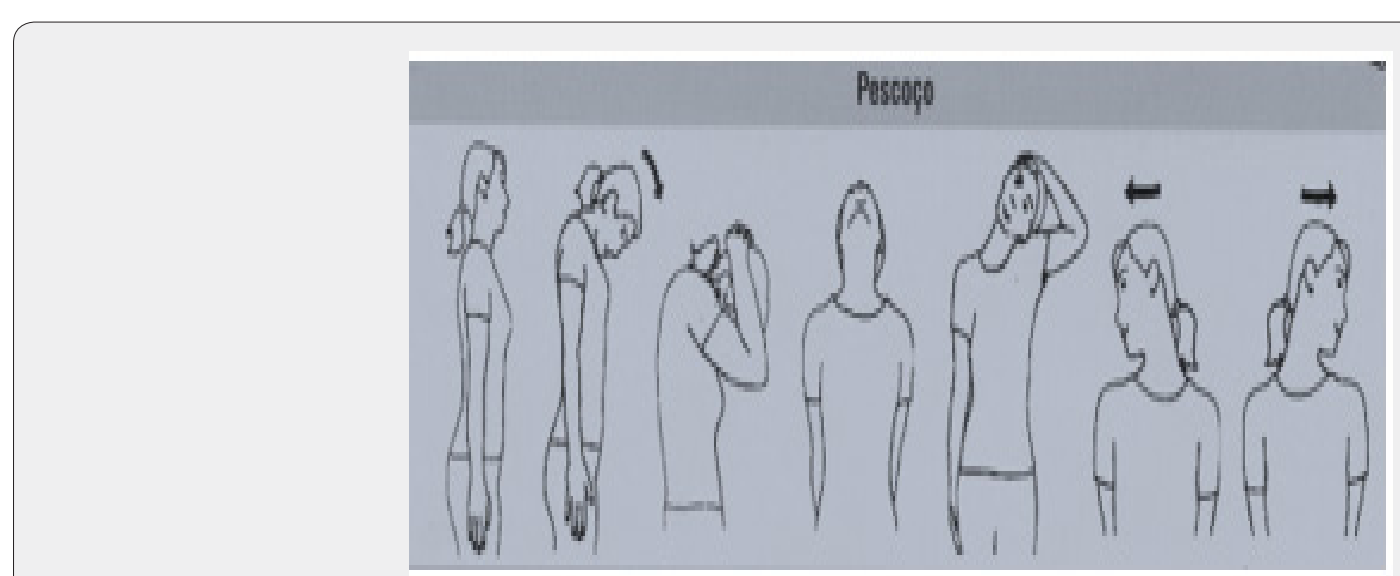

Figure 1: Stretching of the masseter and cervical muscles were performed.

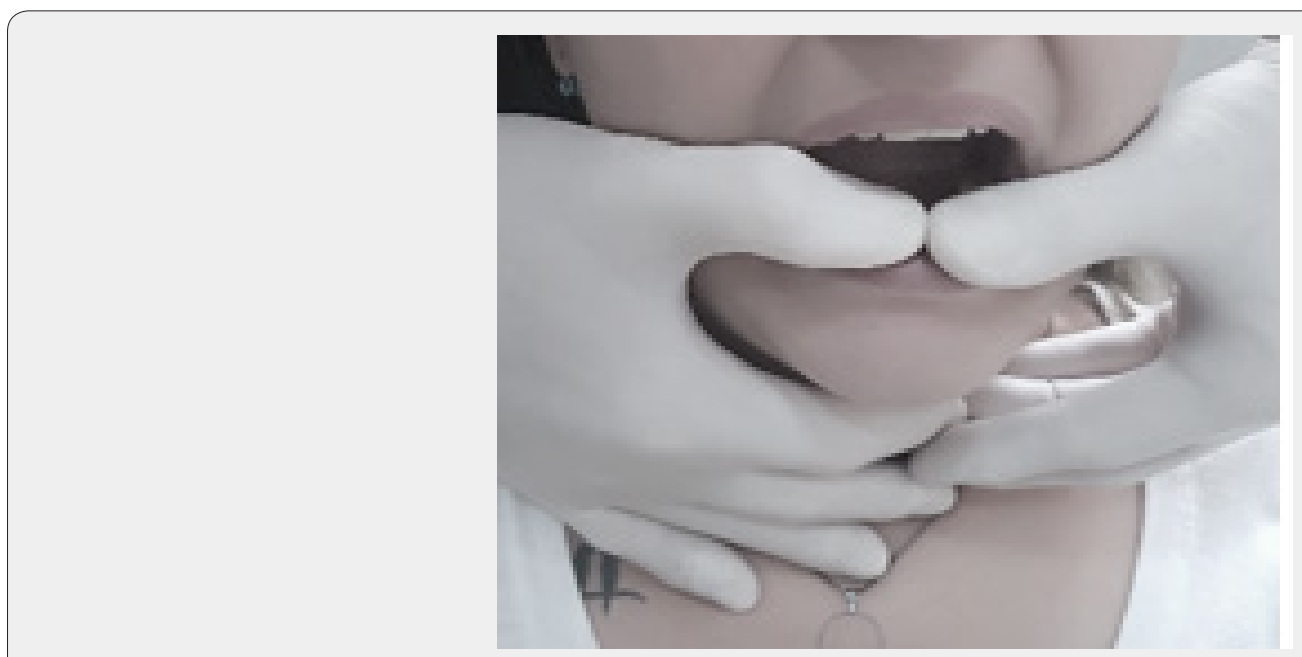

Figure 2: Stretching of the masseter and cervical muscles were performed.

After dry needling, electrotherapy with TENS and thermotherapy with heat application were performed for a period of 20 minutes Butts [7], as shown in Figures 4a \& 4b. Following procedure completion, the patient reported immediate improvement of $90 \%$ and pain intensity 1 on the VAS scale. Exercises were recommended (Figure 5) at least twice a day, along with thermotherapy and analgesic suspension. In the first followup, 30 days after the initial visit, the patient described a significant 


\section{Advances in Dentistry \& Oral Health}

clinical improvement in pain without the daily use of analgesics. Tinnitus appeared twice a week and was related to sudden movements when lifting the head. However, it tended to disappear after 15 to 30 minutes. Cervical stretching, electrotherapy, and thermotherapy were performed for 20 minutes each. At the second follow-up, 98 days after the first, the patient was asymptomatic, although she reported sporadic tinnitus associated with movement. The patient continues to be assisted every six months by a psychiatrist and still uses Rivotril ${ }^{\circledR}$.

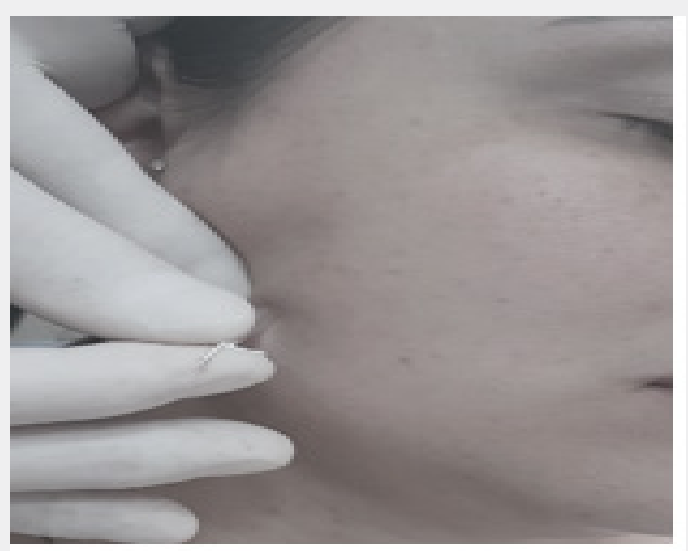

Figure 3: Next, manual intramuscular therapy with dry needling was conducted to disable the myofascial trigger points.

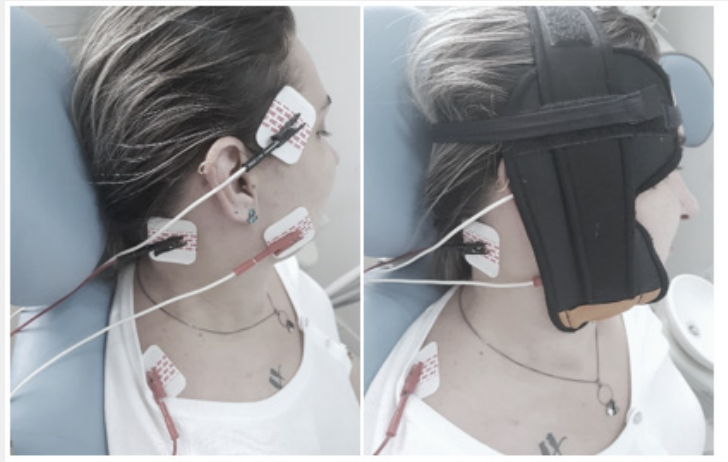

$4 \mathrm{a}$

$4 \mathrm{~b}$

Figure 4: After dry needling, electrotherapy with TENS and thermotherapy with heat application were performed for a period of 20 minutes.

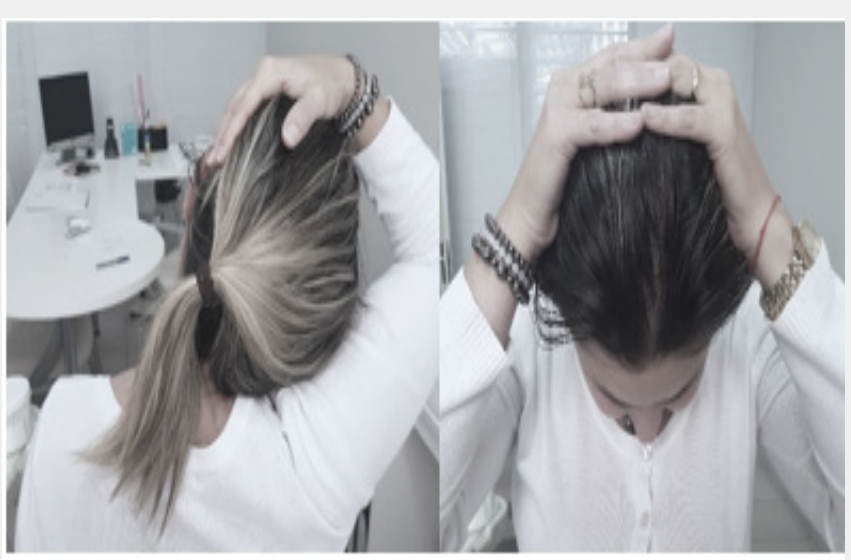

Figure 5: Exercises were recommended at least twice a day, along with thermotherapy and analgesic suspension. 


\section{Final Considerations}

The prevalence of people with orofacial pain ranges from $5 \%$ to $12 \%$ of the adult population Blasco \& Martin [5]. Although there are several methods of treatment and control of this disease, the majority are often ineffective Butts [7]. In many cases, the prescription of centrally acting drugs does not relieve the patient's pain Stone [6]. Oftentimes the patient self-medicates, leading to a change in his pain threshold Dommerholt et al., [8] chronifying pain and the need for medication. Adherence to self-care and physical therapy exercises Shaffer [9] improve vascularization, peripheral analgesia, and central analgesia modulation Butts [7]. Thermotherapy associated with dry needling promotes faster tissue recovery Guimarães [1]. In the case of patient A.C.B.B., proper observation and the use of minimally invasive conduct led to an effective result in a short period of time. It is expected that she will experience pain again, especially on account of her anxiety pattern. However, the patient better understands herself and her pain manifestations, managing them autonomously and almost entirely without medication. When medication is required, administration is conducted punctually, thus improving her quality of life.

\section{References}

1. Guimarães AS (2012) Dor Orofacial entre Amigos, Uma Discussão Científica. São Paulo: Quintessence Editora Ltda 203-205.
2. Schiffman E, Richard Ohrbach, Edmond Truelove, John Look, Gary Anderson, et al. (2014) Diagnostic Criteria for Temporomandibular Disorders (DC_TMD) for Clinical and Research Applications recommendations of the International RDC_TMD C. J Orofac Pain 28(1): 6-27.

3. Gonzalez-Perez LM, Infante-Cossio P, Granados-Nunez M, UrrestiLopez FJ, Lopez-Martos R, et al. (2015) Deep dry needling of trigger points locatedin the lateral pterygoid muscle: Efficacy and safety of treatment for management of myofascial pain and temporomandibular dysfunction. Med Oral Patol Oral CirBucal 20(3): e326-e333.

4. Simons DG, Travell JG, Simons LS (1999) Myofascial pain and dysfunction: the trigger point manual. $2^{\text {nd }}$ ed, Baltimore: Williams \& Wilkins 1.

5. Blasco-Bonora PM, Martín-Pintado-Zugasti A (2017) Effects of myofascial trigger point dry needling in patients with sleep bruxism and temporomandibular disorders: a prospective case series. Acupunct Med 35(1): 69-74.

6. (2018) Sophia Stone. The Scoop on TMD Pharmaceuticals.

7. Butts R, Dunning J, Pavkovich R, Mettille J, Mourad F (2017) Conservative management of temporomandibular dysfunction: A literature review with implications for clinical practice guidelines (Narrative review part 2). Bodyw Mov Ther 21(3): 541-548.

8. Dommerholt J, Finnegan M, Hooks T, Grieve R (2016) A critical overview of the current myofascial pain literature. J Bodyw Mov Ther 20(4): 879-892.

9. Shaffer SM, Brismée JM, Sizer PS, Courtney CA (2014) Temporomandibular disorders. Part 2: conservative management. J Man Manip Ther 22(1): 13-23.

Your next submission with Juniper Publishers will reach you the below assets

- Quality Editorial service

- Swift Peer Review

- Reprints availability

- E-prints Service

- Manuscript Podcast for convenient understanding

- Global attainment for your research

- Manuscript accessibility in different formats

( Pdf, E-pub, Full Text, Audio)

- Unceasing customer service

Track the below URL for one-step submission https://juniperpublishers.com/online-submission.php 